\title{
The Interaction of Guarantees, Surplus Distribution, and Asset Allocation in With Profit Life Insurance Policies
}

\author{
Alexander Kling* \\ Institut für Finanz- und Aktuarwissenschaften, \\ Helmholtzstr. 22, 89081 Ulm, Germany \\ phone: +49 731 5031242, fax: +49 7315031239 \\ email: a.kling@ifa-ulm.de \\ Andreas Richter \\ Assistant Professor \\ Illinois State University, \\ Kingsridge Ct. B, 61761 Normal, IL, USA \\ email: arichter@ilstu.edu \\ Jochen Ruß \\ Managing Director, \\ Institut für Finanz- und Aktuarwissenschaften, \\ Helmholtzstr. 22, 89081Ulm, Germany \\ email: j.russ@ifa-ulm.de
}

This version: 5/30/2005

${ }^{*}$ attending and presenting author. 


\title{
The Interaction of Guarantees, Surplus Distribution, and Asset Allocation in With Profit Life Insurance Policies
}

\author{
Alexander Kling, Andreas Richter, Jochen Ruß \\ This Version: 5/30/2005
}

\begin{abstract}
Traditional life insurance policies in many markets are sold with minimum interest rate guarantees. In products which are predominant e.g. in the German market, there is a socalled cliquet-style (or year-by-year) guarantee, where the guaranteed return must be credited to the policyholder's account each year. Usually, life insurers try to provide this guaranteed rate of interest plus some stable surplus on the policyholder's account every year by applying the so-called average interest principle: Building up reserves in years of good returns on assets and using these reserves to keep surplus stable in years of low returns.

In the current low interest environment, insurance companies in many countries are forced to provide high guaranteed rates of interest to accounts to which a big portion of past years' surplus has already been credited. This development illustrates the additional risk that a cliquet-style guarantee incurs, compared with a point-to-point guarantee, by limiting the insurance company's flexibility. So far, only very little literature exists that deals with these guarantees.

The primary focus of most existing literature in this area is on the fair (i.e. riskneutral) valuation of life insurance contracts. Since most insurers do not apply risk-neutral (or risk-minimizing) hedging strategies, an analysis of the resulting risks seems very important. Therefore, the present paper will concentrate on the risk a contract imposes on the insurer, measured by shortfall probabilities under the so-called "real-world probability measure P". We develop a rather general model and analyze the impact interest rate guarantees have on the risk exposure of the insurance company and how default risks depend on characteristics of the contract, on the insurer's reserve situation and asset allocation, on management decisions, as well as on regulatory parameters. In particular, the interaction of the parameters is analyzed yielding results that should be of interest for insurers as well as regulators.
\end{abstract}

Keywords: with profit life insurance, interest rate guarantees, shortfall probability, Monte Carlo simulation, 


\section{Introduction}

Traditional (i.e. not variable) life insurance policies in many markets are sold with minimum interest rate guarantees. Quite common are guarantees on a point-to-point basis: At maturity of a contract, the policyholder is guaranteed the amount equivalent to the result of a process which credits a certain minimum interest rate to the insured's account in every single year. However, an insurer's investment underperformance (relative to the guaranteed rate) for some of the years of a contract's lifetime would be tolerable so long as the minimum amount is met in the end. This provides the insurer with the possibility to compensate bad investment results by positive results in other years. On the other hand, of course, this type of guarantee poses risk on the policyholder as it leaves the insurer with considerable flexibility in crediting interest to specific accounts. In so far as there is discretion with respect to the accounts to which interest is credited or with respect to whether returns are passed on to the insureds at all, this type of guarantee sets incentive to meeting short-term obligations while at the same time neglecting "young” contracts.

This incentive problem can be reduced by means of incorporating a different type of interest rate guarantee: In the case of a so-called cliquet-style guarantee, as, e.g., required by the German regulatory framework, the guaranteed return must be credited to the policyholder's account each year. Obviously, the resulting reduction in risk for the policy owner comes at the cost incurred by the reduction of the insurer's flexibility in its investment decisions.

Usually, as long as this is permitted by the market, life insurers try to provide the guaranteed rate of interest plus some surplus on the policyholders' account every year. Insurers apply a strategy which is often referred to as the average interest principle (see, 
e.g., Grosen and Jorgensen, 2000): Companies attempt to hold the surplus credited to the policyholders' account as constant as possible, in order to signal stability and low risk compared to other personal investment options an insured would have. This is achieved through building up of reserves (mostly asset valuation reserves) in years of good returns on assets and using these reserves to keep surplus stable in years of low (or even negative) returns on assets. A reasonable model of the distribution mechanism in with profit life insurance contracts should include this averaging mechanism.

Superficially, the long-term use of the strategy described above suggests that the minimum interest rate guarantee is obsolete. For a significant period in the past, it seemed as if the minimum guaranteed interest rates required by regulators were so low that insurance companies would exceed these values anyway without at all perceiving the minimum requirement as a restriction. Consequently, it appears that until rather recently life insurers have not charged a premium for an interest rate guarantee (see Grosen and Jorgensen, 2002, p. 64). The process of averaging returns over time worked rather well since market interest rates were, over a long time span, significantly higher than the guaranteed rates. In recent years, however, low market interest rates and plunging stock markets have caused trouble for insurance companies. In the changed environment, they now have to provide comparably high guaranteed returns to accounts to which already a substantial amount of the surplus of past years has been credited. Under these circumstances, minimum interest rate guarantees have suddenly become a threat to insurers’ solvency.

These developments illustrate the relevance of analyses of the impact of interest rate guarantees on these contracts and their interaction with other parameters. A key rationale 
for the regulation of insurance markets is to reduce or limit insurers' risk of insolvency. Minimum interest requirements, however, obviously generate a restriction which may increase insolvency risk. Particular emphasis therefore needs to be put on the interdependence between interest rate guarantees and the likelihood of default.

A number of papers have recently addressed interest rate guarantees, such as Briys and de Varenne (1997), Grosen and Jorgensen (2000), Jensen et al. (2001), Miltersen and Persson (2001), Hansen and Miltersen (2002), Grosen and Jorgensen (2002), Bacinello (2003), and Tanskanen and Lukkarinen (2003).

For a point-to-point guarantee framework, Briys and de Varenne (1997) compute closed-form solutions for market values of liabilities and equities. In their model the policy owner receives a guaranteed interest and is also credited a bonus, determined as a certain fraction of net financial gains (when positive). They provide an equilibrium condition, which reflects the interdependencies between these two parameters, assuming fair valuation of the contract in a risk-neutral evaluation framework. The paper also addresses the impact of interest rate guarantees on the company's risk exposure by analyzing interest rate elasticity and duration of insurance liabilities.

Contrasting the just-mentioned approach, Grosen and Jorgensen (2000) consider cliquet-style guarantees and introduce a model that takes into account an insurer's use of the average interest principle. In addition to a policy reserve (the customer's account) they introduce a "bonus reserve", a buffer that can be used to smoothen future bonus distributions. They analyze a mechanism that credits bonus to the customer's reserve based upon the current ratio of bonus reserve over policy reserve. A bonus is paid only if this ratio exceeds a given threshold. Thus, the actual distribution of surplus indirectly reflects current 
investment results but primarily focuses on the company's ability to level out insufficient results in the future. The authors decompose the contract into a risk free bond, a bonus and a surrender option. They compute contract values by means of Monte Carlo simulation, and also calculate contract default probabilities for different parameter combinations. ${ }^{1}$ However, they calculate default probabilities under the risk neutral probability measure $Q$. Therefore, the numerical results are of only limited explanatory value.

Miltersen and Persson (2001) also use a cliquet-style framework and allow for a portion of excess interest to be credited not directly to the customer's account but to a bonus account. In their model, the interest that exceeds the guaranteed rate is - if positive divided into three portions that are credited to the insured's account, the insurer's account, and to a bonus account. In case of investment returns below the guaranteed rate, funds are moved from the bonus account into the policy owner's account. Thus, the bonus account is available for smoothing returns over time. Unlike in the Grosen and Jorgensen (2000) model, however, the buffer consists of funds that have already been designated to the particular customer: Any positive balance on the bonus account is credited to the policy owner when the contract expires. This is used to model so-called "terminal bonuses". In this setting, Miltersen and Persson (2001) derive numerical results on the influence of various parameters on the contract value. ${ }^{2}$

1 Jensen et al. (2001) extend the findings of Grosen and Jorgensen (2000). As one extension, among others, they introduce mortality risk. Another paper that incorporates mortality risk as well as the surrender option is Bacinello (2003).

2 Contrasting the mechanism discussed in Miltersen and Persson (2001), life insurance contracts often employ a distribution policy that does not accumulate undistributed surplus on an individual basis, but for a greater pool of customers. A model that allows for this technique can be found in Hansen and Miltersen (2002). 
Grosen and Jorgensen (2002) discuss a model based upon the framework used by Briys and de Varenne (1997). They incorporate a regulatory constraint for the insurer's assets according to which the company is closed down and liquidated if the market value of assets drops below a threshold at any point in time during the life of the policy. Their results suggest that the introduction of the regulatory constraint significantly reduces the value of the shareholders' default put option and thereby an insurer's incentive to change its assets' risk characteristics to the policyholders' disadvantage.

While some of the above-mentioned papers incorporate the risk of a contract's or the insurer's default, the primary focus is on the fair (i.e. risk-neutral) valuation of the life insurance contract. Since most insurers do not or can not apply optimal hedging strategies in their asset allocation, an analysis of the resulting risks seems very important. Therefore, this work will concentrate on the risk a contract imposes on the insurer, measured by means of shortfall probabilities under the so-called "real-world probability measure $P$ ". We are interested in the impact interest rate guarantees have on the exposure of the insurance company and how default risks depend on characteristics of the contract, on the insurer's reserve situation and asset allocation, on management decisions, as well as on regulatory parameters. We will assume cliquet-style guarantees throughout this paper. Certain other features of our model are motivated by the German regulatory framework, but model specifications could easily be changed to reflect other countries' situations.

The paper is organized as follows. In section 2, we introduce our model. We use a simplified illustration of the insurer's financial situation. Before we describe the surplus distribution mechanism, we present our model for the assets and the insurance contract. 
Section 2 concludes with introducing shortfall probabilities as the relevant risk measure for this work.

In section 3, we present the results of our analysis. We examine the influence of the above-mentioned parameters on shortfall probabilities and analyze their interaction. The results should be of interest for insurers as well as for regulators.

Section 4 gives a short summary of the most important results and an outlook on further research options.

\section{The model framework}

This Section introduces our model. We keep it as simple as possible to be able to focus on the basic effects. First, we consider the reserve situation of the insurance company’s balance sheet. Then, we introduce our model for the financial market and refer to some specific aspects of German regulation. Afterwards, the insurance contract considered and the corresponding liabilities are defined. Our analysis of the interaction of assets and liabilities takes into account the ability of insurance companies to build up and dissolve hidden reserves over time. We assume that insurance companies can buy and sell assets in order to reduce hidden reserves without any restrictions. However, the decision whether an increase in the market value of assets increases the book value or the hidden reserves is subject to some restrictions. Finally, we define shortfall probabilities as the relevant risk measure for the following analysis.

\subsection{The insurer's initial situation}

We use a simplified illustration of the insurer's financial situation given in figure 1. 


\begin{tabular}{c|c} 
Assets & Liabilities \\
\hline$A_{t}$ & $L_{t}$ \\
& $R_{t}$ \\
\hline$A_{t}$ & $A_{t}$
\end{tabular}

Figure 1 Model of the insurer's financial situation

By $A_{t}$, we denote the market value of the insurer's assets at time $t$. The liability side comprises two entries: $L_{t}$ is the time $t$ book value of the policyholders' account or, in other words, the policy reserve which also coincides with the book value of the assets. The second account is the reserve account $R_{t}$ which is given by $R_{t}=A_{t}-L_{t}$. Although it might consist of other components as well, e.g. firm's capital, we refer to $R_{t}$ as the asset valuation reserves or hidden reserves.

Payments to equity holders are paid out and therefore leave the company. This is reflected by subtracting the corresponding amount from $A_{t}$. To simplify notation, we assume that such payments occur only once a year, at times $t=1,2, \ldots, T$, where $T$ denotes the considered time horizon.

\subsection{The financial model}

The insurer's assets are invested in a portfolio containing stocks and bonds. We think of both as risky assets with known expected rate of return, volatility and correlation. We assume a finite time horizon $T$ and a complete, frictionless and continuous market. Ignoring payments to equity holders for a moment, we let $A_{t}$ follow a geometric Brownian motion

$$
\frac{d A_{t}}{A_{t}}=\mu(t) d t+\sigma(t) d W_{t},
$$


where $W_{t}$ denotes a Wiener process on some probability space $(\Omega, \Sigma, P)$ with a filtration $F$, to which $W$ is adapted. Both, $\mu$ and $\sigma$ are deterministic but can be time dependent. In our numerical analysis in Section 3, we assume $\mu=8 \%$ and $\sigma=20 \%$ for the stock portion of the portfolio as well as $\mu=5 \%$ and $\sigma=3.5 \%$ for the bond portion of the portfolio. Furthermore, we assume stock and bond returns to be slightly negatively correlated with a correlation coefficient of $\rho=-0.1 .^{3}$ Thus, drift and volatility of the portfolio can be calculated for any given asset allocation.

For a given $A_{0}>0$, the solution of (1) is given by

$$
A_{t}=A_{0} e^{\int_{0}^{t} \mu(s)-\frac{\sigma^{2}(s)}{2} d s+\int_{0}^{t} \sigma(s) d W_{s}}
$$

and, hence, we have

$$
A_{t}=A_{t-1} \cdot e^{\int_{t-1}^{t} \mu(s)-\frac{\sigma^{2}(s)}{2} d s+\int_{t-1}^{t} \sigma(s) d W_{s}}
$$

If there are any dividend payments $D_{t}$ to equity holders at time $t$, we let $A_{t}^{-}$denote the value of the assets before these payments leave the company and $A_{t}^{+}$the value of the assets after these payments left the company. Thus, we get (for $t=1,2, \ldots, T$ )

$$
A_{t}^{-}=A_{t-1}^{+} \cdot e^{\int_{t-1}^{t} \mu(s)-\frac{\sigma^{2}(s)}{2} d s+\int_{t-1}^{t} \sigma(s) d W_{s}} \quad \text { and } \quad A_{t}^{+}=A_{t}^{-}-D_{t}
$$

which can be used handily in Monte Carlo algorithms.

3 We used data of a German stock index (DAX) and a German bond index (REXP) of the years 1988 to 2003 to get estimates for drift, volatility and correlation of stocks and bonds. Since historical bond returns seem to be too high compared to current low interest rates, we reduced the drift for the bond portion to $5 \%$. 
The portion of stocks contained in $A_{t}$ is denoted by $s_{t}$. We do not consider any transaction fees for buying and selling assets. In our numerical analysis, we assume $s_{t}=s$ to be constant.

\subsection{The insurance contract}

For the sake of simplicity, we look at a very simple life insurance contract, a singlepremium term-fix insurance and ignore any charges. The premium $P$ is paid at $t=0$. A benefit is paid at time $T$, no matter if the insured is still alive or not. Thus, there are no mortality effects to be considered. The benefit paid at time $T$ depends on the development of the insurer's liabilities and is given by $P \frac{L_{T}}{L_{0}} \cdot{ }^{4}$

\subsection{Regulatory and legal requirement}

In what follows, we include important features of the current German regulatory and legal framework in our model. Nevertheless, specific aspects of other countries could be considered analogously.

Currently, German life insurance companies guarantee policyholders a minimum rate of interest of $g=2.75 \% .^{5}$ This guarantee is given as a cliquet-style guarantee for the whole term of the policy and may not be reduced even if regulators change the guaranteed

4 We ignore mortality effects as well as charges for any mortality benefit that exceeds the policy value at time of death. Although this might seem inappropriate in the analysis of a life insurance company's assets and liabilities, it is justified under the following two assumptions: 1) The risk premiums are calculated properly such that the insurer incurs no significant profit or loss upon death. 2) On average, new business roughly compensates for mortality and surrenders. Under these "steady state" assumptions, the term fix contract and the corresponding assets are an approximation for the liabilities and assets of the whole insurance company.

5 More precisely, there is a maximum rate of return, policy reserves may be calculated with. Since this rate is used for almost all products and since surrender values have to be close to policy reserves, this implies that insured have a year by year guarantee of this interest rate on their account value. 
interest rate for new business. Thus, all policies that have been sold when guaranteed rates were higher are still entitled to the guaranteed rate that prevailed when the contracts were sold: $3.25 \%$ or even $4 \%$ p.a.

Furthermore, the law requires that at least $\delta=90 \%$ of the earnings on book values have to be credited to the policyholders' accounts. This so-called "minimum participation rate" was introduced to make sure that policyholders are not put at a disadvantage compared to the shareholders.

\subsection{Development of the financial situation over time}

As mentioned above, we consider a year-by-year guarantee on the liabilities. Given the liabilities $L_{t-1}$ at time $t-1$, the guaranteed liabilities $L_{t}^{g}$ at time $t$ are given by

$$
L_{t}^{g}=L_{t-1}(1+g)
$$

Since earnings on book value are subject to accounting rules, they are not necessarily equal to the earnings on market value $A_{t}^{-}-A_{t-1}^{+}$. For instance, by using the "lower of cost or market principle”, a company in Germany can "hide” a rise in a stock price in order to increase asset valuation reserves. This can, however, only be done with parts of the earnings in market value since the decision whether an increase in the market value of assets should increase the book value or the hidden reserves is subject to some restrictions. These restrictions are different for every asset class and therefore rather complex. In our model, we simplify by assuming that at least a portion $y$ of the increase in market value has 
to be identified as earnings in book values in the balance sheet. ${ }^{6}$ This means that at least the amount $\delta \cdot y\left(A_{t}^{-}-A_{t-1}^{+}\right)$has to be credited to the policy reserve. The parameter $y$ therefore represents the degree of "restriction in asset valuation" given by the regulator.

Furthermore, the insurer can reduce reserves (i.e. increase the book value of assets) without any restrictions by selling assets whose market value exceeds the book value.

The decision, which surplus (i.e. interest exceeding the guaranteed rate) is given to the insured has to be made by the insurance company's management every year. Our general model allows for any management decision rule at time $t$ that is $F_{t}$-measurable, i.e. that depends only on information available at time $t$. Therefore, it would be possible to analyze the effect of different surplus distribution mechanisms on the financial situation of the insurance company. In the numerical analysis, however, we will focus on one distribution methodology that seems to prevail in Germany: In the past, German insurance companies used to credit a rather constant rate of interest to the policy reserves over years. When interest rates came down and stayed low and stock markets plunged, they used the hidden reserves that had been accumulated in earlier years to keep the surplus stable. Only when the reserves reached a rather low level, they started reducing the surplus. Therefore, we apply the following decision rule:

A target rate of interest $z>g$ is credited to the policy reserves, as long as the socalled reserve quota $x_{t}=\frac{R_{t}}{L_{t}}$ stays within a given range $[a ; b]$. Only if the reserve quota becomes too low (too high) will the surplus be reduced (increased).

\footnotetext{
${ }^{6}$ Note that for $y=0$, the insurance company is totally free in determining the earnings on book values.
} 
If the target rate of interest $z$ is given to the insured at time $t$ (i.e. a surplus of $(z-g) L_{t-1}$ is credited to the insured's account), the liabilities $L_{t}$ are given by

$$
L_{t}=(1+z) L_{t-1}=L_{t}^{g}+(z-g) L_{t-1}
$$

As mentioned above, our model also allows for dividends that are paid to the owners of the insurance company. Again, the general model allows for any $F_{t}$-measurable dividend payment. For the numerical examples, we assume that the dividend amounts to a portion $\alpha$ of any surplus credited to the policy reserves. Thus, if the target rate $z$ is given to the insured, we get

$$
A_{t}^{+}=A_{t}^{-}-\alpha(z-g) L_{t-1}
$$

and

$$
R_{t}=A_{t}^{+}-(1+z) L_{t-1}
$$

The condition for the reserve quota $a \leq x \leq b$, i.e. $a \leq \frac{R_{t}}{(1+z) L_{t-1}} \leq b$ is fulfilled if and only if

$$
((1+a)(1+z)+\alpha(z-g)) L_{t-1} \leq A_{t}^{-} \leq((1+b)(1+z)+\alpha(z-g)) L_{t-1}
$$

In this case, exactly the target rate of interest $z$ is credited to the insurance contracts. For the other cases, we use the following decision rules: ${ }^{7}$

\footnotetext{
${ }^{7}$ Other $F_{t}$-measurable decision rules that may apply for certain companies can also be implemented in the
} model. 
If crediting the target rate $z$ leads to a reserve quota below $a$ and crediting the guaranteed rate $g$ leads to a reserve quota above $a$, then the company credits exactly that rate of interest to the policy holders that leads to $x_{t}=a$. Hence, we have

$$
L_{t}=(1+g) L_{t-1}+\frac{1}{1+a+\alpha}\left[A_{t}^{-}-(1+g)(1+a) L_{t-1}\right]
$$

and

$$
A_{t}^{+}=A_{t}^{-}-\frac{\alpha}{1+a+\alpha}\left[A_{t}^{-}-(1+g)(1+a) L_{t-1}\right]
$$

If even crediting the guaranteed rate of interest leads to a reserve quota level below $a$, i.e.,

$$
A_{t}^{-}<(1+a)(1+g) L_{t-1}
$$

then the guaranteed rate of interest is provided to the policyholders and the equity holders do not receive anything, i.e.,

$$
L_{t}=(1+g) L_{t-1} \text { and } A_{t}^{+}=A_{t}^{-}
$$

If crediting the target rate of interest $z$ leads to a reserve quota above the upper limit $b$, the company credits exactly that rate of interest to the policyholders that meets the upper reserve quota boundary $x_{t}=b$, i.e.,

$$
L_{t}=(1+g) L_{t-1}+\frac{1}{1+b+\alpha}\left[A_{t}^{-}-(1+g)(1+b) L_{t-1}\right]
$$

and 


$$
A_{t}^{+}=A_{t}^{-}-\frac{\alpha}{1+b+\alpha}\left[A_{t}^{-}-(1+g)(1+b) L_{t-1}\right]
$$

Finally, we want to check whether these rules comply with the minimum participation rate, i.e. whether at least the amount $\delta \cdot y\left(A_{t}^{-}-A_{t-1}^{+}\right)$is credited to the policy reserves. Whenever our decision rules lead to a violation of this rule, i.e.

$$
L_{t}-L_{t-1}<g L_{t-1}+\left[\delta \cdot y\left(A_{t}^{-}-A_{t-1}^{+}\right)-g L_{t-1}\right]
$$

we increase the surplus such that the minimum participation rate is met by letting

$$
L_{t}=(1+g) L_{t-1}+\left[\delta \cdot y\left(A_{t}^{-}-A_{t-1}^{+}\right)-g L_{t-1}\right]
$$

and

$$
A_{t}^{+}=A_{t}^{-}-\alpha\left[\delta \cdot y\left(A_{t}^{-}-A_{t-1}^{+}\right)-g L_{t-1}\right]^{8}
$$

\subsection{Shortfall}

We consider the life insurance company to default if at any balance sheet date $t=1,2, \ldots, T$, the market value of the assets is below the book value of the liabilities, i.e., if

$$
R_{t}<0
$$

We let the stopping time $\tau$ be the first balance sheet date, where a default happens or $\tau=T+1$ if $R_{t} \geq 0 \quad \forall t \in\{1, \ldots, T\}$.

${ }^{8}$ Note that this can only happen, if the insurance company does not have enough freedom to „hide“ asset price gains in hidden reserves, i.e. if the amount $\delta \cdot y\left(A_{t}^{-}-A_{t-1}^{+}\right)$that has to be shown as an increase in book value as described earlier in this section, leads to a higher book value than desired by the insurer.

${ }^{9}$ Recent change in German legislation allowed for so-called negative hidden reserves, i.e. book values above market values under certain circumstances. In this model, we neglect the resulting effects. 
The shortfall probability $p_{t}=P\left(\tau \leq T \mid F_{t}\right)$ is defined as the probability that a shortfall occurs at some balance sheet date after the current time $t$, given the information available at time $t$. It depends on

- parameters describing the regulatory framework, i.e. the guaranteed rate of interest $g$, the minimum participation rate $\delta$, the restriction in asset valuation $y$,

- parameters describing the insurance company's financial situation and management decisions, i.e. the current reserve situation $x$, the portion of stocks in the asset portfolio $s,{ }^{10}$ the portion of surplus that is paid out to equity holders $\alpha$, the target rate of interest $z$, the target range for the reserve quota $[a ; b]$

- capital market parameters, i.e. drift $\mu$ and volatility $\sigma$ of the asset portfolio, and

- the considered time horizon, i.e. the remaining term to maturity of the product T-t.

\section{Analysis}

In what follows, we will analyze the effect of the different parameters on the shortfall probability. It can easily be shown analytically that whenever a parameter is changed that leads to an increase in liabilities and does not influence (or even decrease) the development

\footnotetext{
${ }^{10}$ This could easily be replaced by some asset allocation strategy if we allow a changing asset allocation.
} 
of the assets, the shortfall probability increases, and vice versa. Therefore, $p_{t}$ is (ceteris paribus) increasing in $g, z, \delta$, and $\alpha$ and decreasing in $x, a$, and $b$.

In what follows, we will perform more detailed analyses focusing on the interaction of several parameters. Since in these cases no analytical solutions exist, we use Monte Carlo simulation methods performing 10,000 simulations per analyzed combination of parameters in order to calculate the shortfall probability.

For all our calculations we fix $T=10,[a ; b]=[5 \% ; 30 \%], \delta=90 \%$, and $\alpha=3 \%$, unless stated otherwise.

\subsection{The influence of the initial reserve situation}

In a first step, we calculate the shortfall probability $p_{0}(x)$ as a function of the insurer's initial reserve quota for different values of the guaranteed rate of interest $g \in\{2.75 \%, 4 \%\}^{11}$ and different asset allocations $(s \in\{10 \%, 30 \%\})$. We assume the target rate of interest $z$ to equal $5 \%$ and consider different values for the restriction in asset valuation $y$.

For values of $y$ close to $100 \%$, it turns out that for companies with low initial reserves shortfall probabilities are close to $100 \%$. This is not very surprising because in this case there is almost no chance for the insurance company to increase its reserve account $R_{t}$ over time. In years of high asset returns, almost all earnings are either given to policyholders or shareholders leaving little potential to build up reserves. On the other hand, in years of low asset returns, reserves are reduced to provide the guaranteed rate of interest to the

\footnotetext{
11 This corresponds to the rate applicable in Germany to new business starting January 1, 2004 (2.75\%) and to contracts taken out between January 1995 and June 2000 (4\%).
} 
policyholders' accounts. This shows that high values of $y$ pose a high risk on an insurance company, i.e. highly restrictive accounting rules in connection with high minimum participation rates would be very dangerous for insurance companies offering cliquet-style guarantees. This issue will be analyzed in more detail in Section 3.6.

Figure 2 shows the shortfall probability as a function of the initial reserve situation $x$ for a target rate of interest $z=5 \%$ and different values of the guaranteed rate of interest $(\mathrm{g}=$ $2.75 \%$ and $g=4 \%)$ and different stock ratios $(s=10 \%$ and $s=30 \%)$ assuming that at least $y=50 \%$ of the earnings on market value have to be identified as earnings on book value.
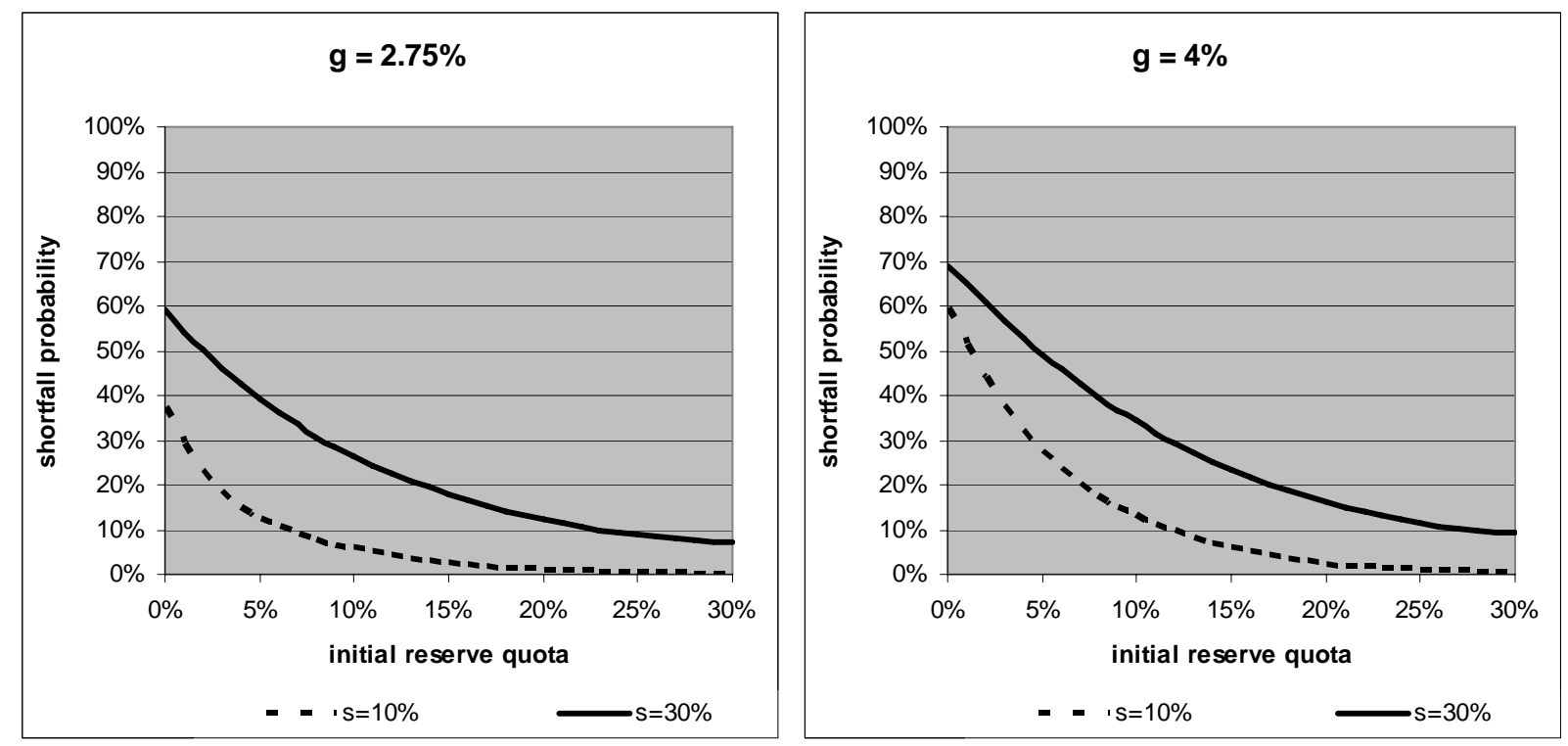

Figure 2 Shortfall probability as a function of the insurer's initial reserve quota for $y=50 \%$

Of course, the shortfall probability is decreasing with increasing initial reserves. One can see from both pictures that companies with low reserves have to have low stock ratios in order to keep shortfall probabilities low.

It is not surprising that, all other things equal, contracts with a guaranteed rate of interest of $4 \%$ pose a higher risk to the insurance company than those with a guaranteed 
rate of $2.75 \%$, since there is less freedom in crediting profits and building up reserves. It is noticeable, though, that the absolute values of the shortfall probabilities are rather high in both cases.

Further analysis shows that changing $y$ from $50 \%$ to $0 \%$ hardly changes the results at all. This suggests that it seems sufficient to have some (as opposed to complete) freedom in determining earnings on book values, e.g. the possibility to hide $50 \%$ of the earnings on market value. Since $y=50 \%$ seems to be a reasonable value that is consistent with accounting rules that prevail, e.g., in Germany we keep this parameter fixed for the remainder of this analysis unless stated otherwise.

\subsection{The interaction of reserve situation and asset allocation}

We now assume that the insurance company has some tolerable level of shortfall probability, here $p_{0}(x, s)=10 \%$. We analyze the interaction of initial reserve situation and asset allocation by calculating which combinations of $x$ and $s$ lead to this given shortfall probability. This answers the question of which reserve quota is necessary to back a given asset allocation, or (equivalently) which asset allocation is admissible for a given reserve situation.

Figure 3 displays the interaction between the insurer's initial reserve quota and the stock ratio $s$ for different values of the guaranteed rate of interest ( $g=2.75 \%$ and $g=4 \%$ ) and different values of the target distribution $(z=5 \%$ and $z=6 \%)$. 

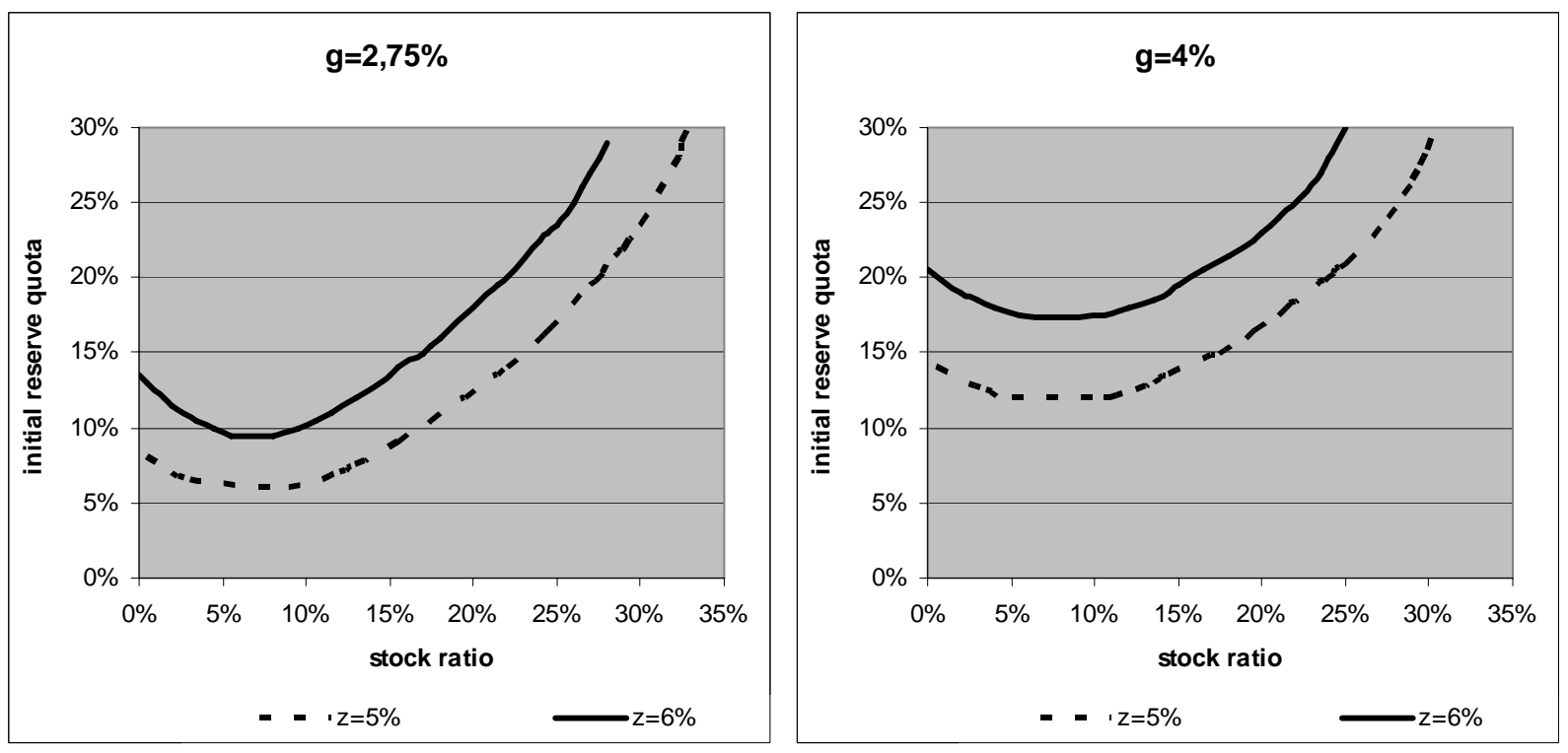

Figure 3 Insurer's initial reserve quota as a function of the stock ratio s

For a tolerable shortfall probability of $10 \%$ and contracts with guarantee $g=2.75 \%$ and target rate of interest $z=5 \%$, we can see from the left part of Figure 3 that for a stock ratio of $s=10 \%$ initial reserves of $x=7 \%$ are sufficient. If the insurer wants to invest $30 \%$ of the assets in stocks, $25 \%$ initial reserves are required.

Since stocks and bonds are both risky assets that are not perfectly correlated, it is not the portfolio with $0 \%$ stocks that minimizes risk. In our model, any asset allocation with a stock ratio below the minimum risk portfolio is dominated as it represents greater risk while providing lower returns than the higher stock ratios. As a rule of thumb, figure 3 shows that for any increase of $1 \%$ in stock ratio, about $1 \%$ more initial reserves are necessary. Companies with lower initial reserves should have a lower portion of stocks in their asset portfolio.

Clearly, contracts with a higher guaranteed rate of interest are of higher risk for the insurance company than contracts with a low guarantee. In particular, for contracts with a 
guaranteed rate of interest of $4 \%$, insurance companies with a low reserve quota $(<11 \%)$ are not able to achieve a shortfall probability of $10 \%$ at all.

In both pictures, the distance between the two lines for different target rates of interest $z$ hardly depends on $s$ and amounts to approximately 5\% of initial reserves. Therefore, if an insurer wants to keep the shortfall probability stable, the reserve quota should be increased by $5 \%$ if the target rate of interest is increased by $1 \%$.

\subsection{The interaction of surplus distribution and asset allocation}

The target rate of interest $z$ and the asset allocation (characterized by the stock ratio $s$ ) are both subject to management decisions. Therefore, life insurance companies should be highly interested in the effect these parameters have on the shortfall probabilities. Again, we fix some level for the shortfall probability and analyze, which combinations of $z$ and $s$ lead to this level. Since shortfall probabilities are highly sensitive to changes in the reserve situation, companies with $5 \%$ reserves are in a different risk category than companies with $20 \%$ reserves. While for companies with high reserves we can determine combinations of $s$ and $z$ that lead to a shortfall probability of $5 \%$, this is impossible for companies with low reserves. Therefore, we let $p_{0}(z, s)=25 \%$ for the company with low reserves and $p_{0}(z, s)=5 \%$ for the company with high reserves. These different levels of shortfall probabilities have to be kept in mind when looking at the absolute values of the results. Figure 4 shows the results for different values of the initial reserve quota $(x=5 \%$ and $x=$ $20 \%$ ) and different values of the guaranteed rate of interest ( $g=2.75 \%$ and $g=4 \%$ ). 

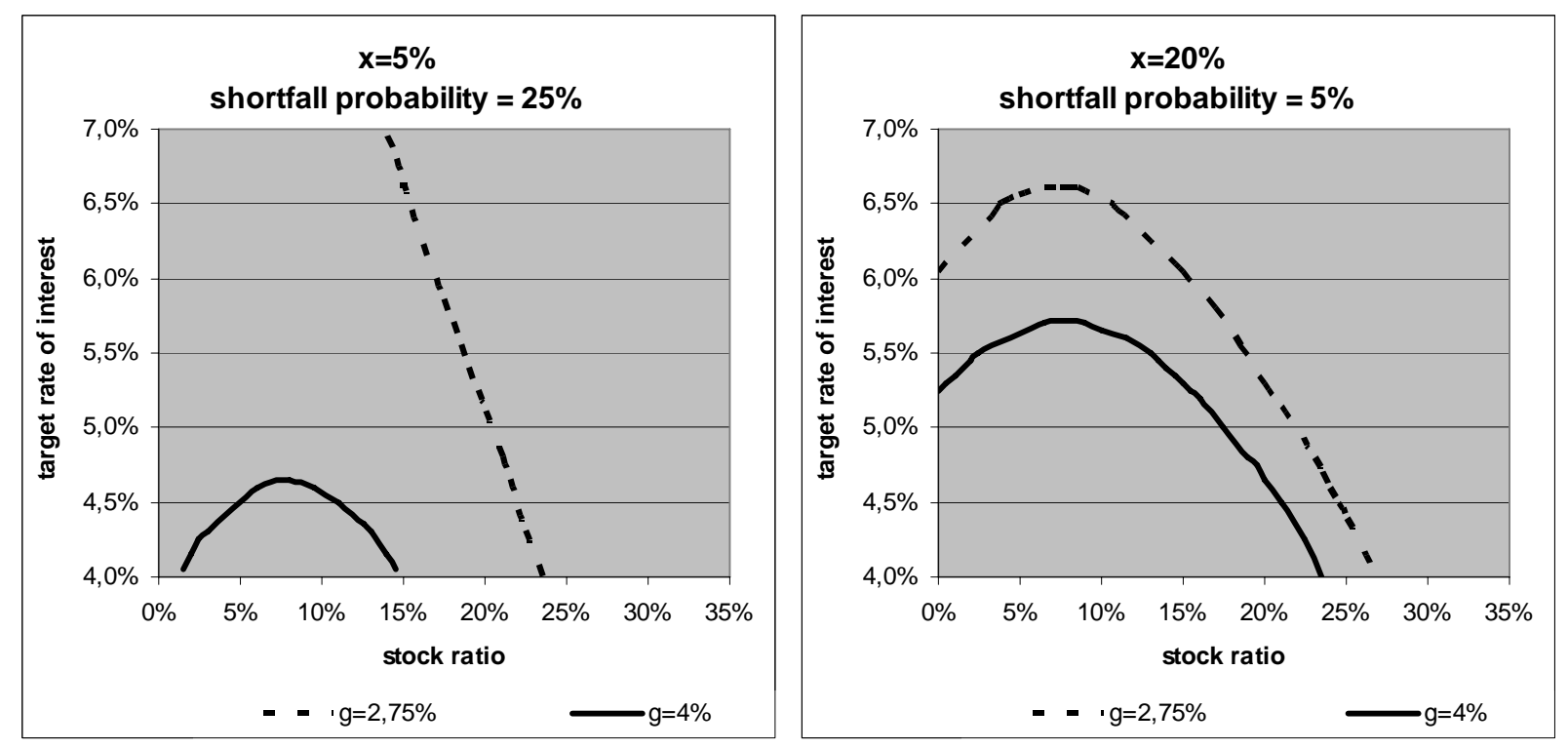

Figure 4 Target rate of interest as a function of the stock ratio $\mathrm{s}$

The results imply that for companies with high reserves, the guaranteed rate of interest is of minor influence. An increase of the guaranteed rate of interest from $2.75 \%$ to $4 \%$ can be compensated by reducing the target rate of interest by $1 \%$ leaving the asset allocation unchanged. Alternatively it can be compensated by reducing the stock ratio by about 3-5\% and leaving the target rate of interest unchanged.

For insurers with low initial reserves, there is however a significant difference between contracts with different guarantees. While (in spite of the very large level of shortfall probability) for a guaranteed rate of return of $4 \%$ only very conservative combinations of $z$ and $s$ are admissible, a guaranteed rate of $2.75 \%$ allows the company to provide $5 \%$ target distribution while holding $20 \%$ stocks (of course at the same high level of shortfall probability).

Furthermore, for companies with low reserves a slight increase in the stock ratio requires a rather significant decrease in the target distribution to keep the shortfall probability stable. For example, if such a company increases their stock ratio from $15 \%$ to 
$20 \%$, it should lower the target rate of interest for contracts with a guaranteed rate of $2.75 \%$ by $2 \%$. A company with higher reserves only needs to reduce the target rate by $0.5 \%$.

Thus, for companies with low reserves, shortfall probabilities are very sensitive with respect to changes in the guaranteed rate of interest and in the stock ratio. Therefore, from a risk management point of view, life insurance companies should lower their stock ratios if reserves tend to go down. In the past, these measures were not taken by most German life insurers leading to the current problems. ${ }^{12}$

\subsection{The interaction of guarantees and asset allocation}

In many countries, regulations exist regarding admissible asset allocations for life insurance companies, e.g. under German regulation, companies are not allowed to hold more than $35 \%$ stocks in their asset portfolio. Regulators often impose the exact same limits on all life insurers, considering neither the guaranteed rate of interest in the companies' insurance liabilities nor the reserve situation. The following analysis will show that a reasonable regulation should consider these issues.

Figure 5 shows combinations of the guaranteed rate of interest and the stock ratio that yield a given shortfall probability. Again, we consider different initial reserve quotas ( $x=$ $5 \%$ and $x=20 \%)$ and different values of the target distribution ( $z=5 \%$ and $z=6 \%)$. Like in Section 3.3, we allow for a shortfall probability of $25 \%$ for companies with low reserves and a shortfall probability of $5 \%$ for companies with high reserves.

\footnotetext{
${ }^{12}$ Contrary, insurers increased their stock ratio hoping to compensate for low interest rates.
} 

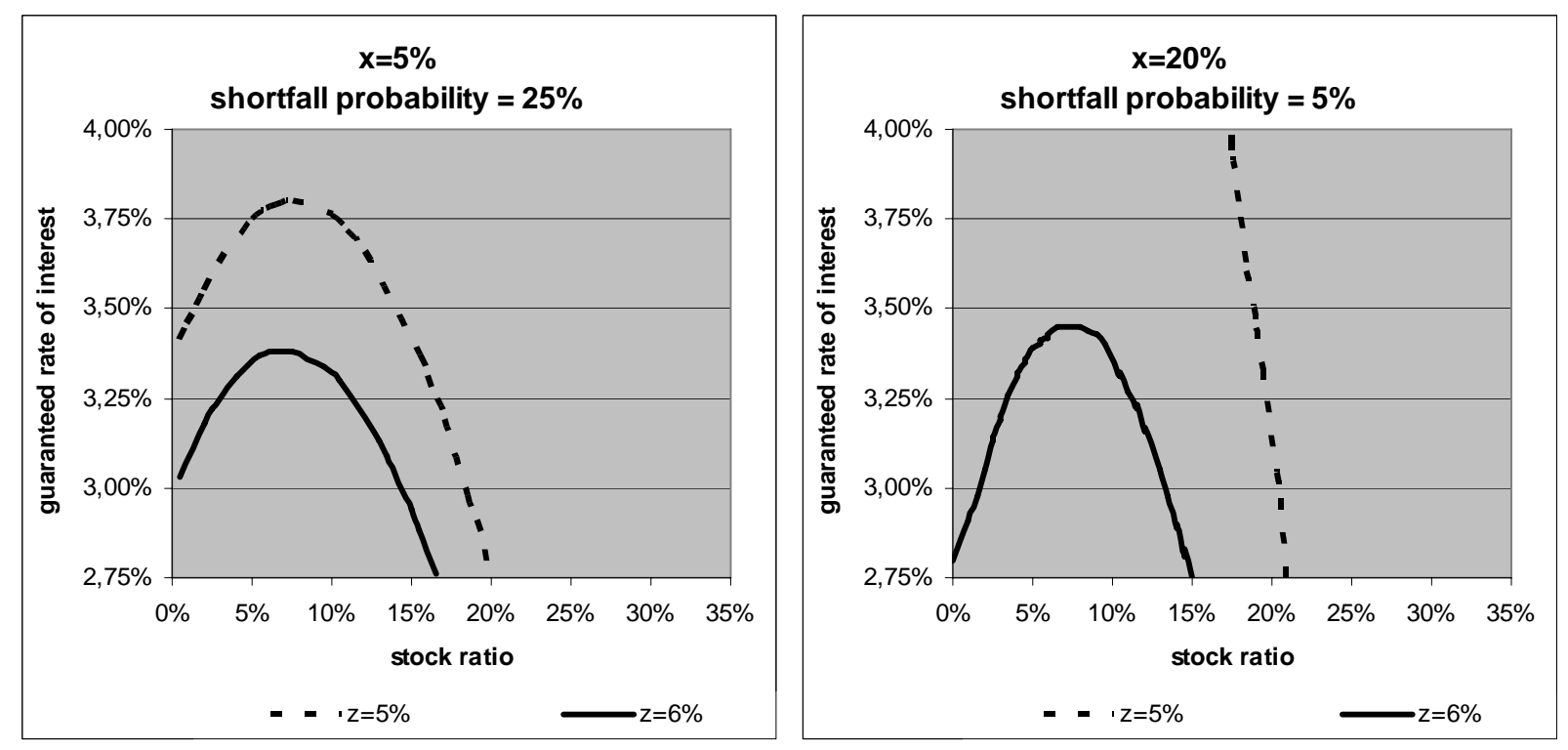

Figure 5 Guaranteed rate of interest as a function of the stock ratio s

Whenever the stock ratio exceeds the stock ratio of the minimum risk portfolio, obviously higher guarantees require lower stock ratios for a given shortfall probability.

From the left part of Figure 5, we can see that an increase in the target rate of interest $z$ from $5 \%$ to $6 \%$ can be compensated by a reduction of the stock ratio of about 3 to 5 percentage points. The two curves on the left side are rather close to each other. This means that changing the target rate of interest has a minor effect for companies with low reserves.

The distance between the two curves on the right suggests that for companies with high reserves the effect of the target rate of interest is significant.

Combining the analyses of Sections 3.3 and 3.4, we find the following remarkable results: Although, of course, the absolute level of the shortfall probability is entirely different for companies with low reserves compared to those with greater reserves, the shortfall probability of a company with low reserves is very sensitive to changes in $g$ and $s$ 
and less sensitive to changes in $z$. The shortfall probability of a company with a high reserve quota is very sensitive to changes in $z$ and $s$ but less sensitive to changes in $g$.

Therefore "static regulations", that impose certain rules and limits for all companies without considering the individual financial strength of a given insurer, appear to make little sense. From a risk management point of view restrictions on $s$ and $g$ only make sense if their interaction and the reserve situation of the company are taken into account, as well. Approaches like the required "Resilience Test" in the $\mathrm{UK}^{13}$ or the recently introduced (but not yet very sophisticated) stress test in Germany seem more reasonable.

\subsection{The interaction of guarantees and surplus distribution}

In the past, when interest rates were quite high in comparison to the guaranteed rates of interest, managing guarantees seemed not to be an important issue. The total interest (guaranteed rate + surplus) credited to the policy reserves was held constant by insurance companies in many countries - not only constant over time but also constant over all "generations of contracts", irrespective of the corresponding guaranteed rate of return. Thus, if an insurer decided to credit $6 \%$ to the insured, contracts with a guaranteed rate of, say, $4 \%$ would have received $2 \%$ surplus while contracts with a lower guaranteed rate of e.g. $2.75 \%$ would have received $3.25 \%$ surplus. In 2004 , for the first time a few insurance companies in Germany started to provide a lower total interest to the policy reserves of contracts with a high guaranteed rate of interest and higher total interest to the policy reserves of contracts with a low guaranteed rate of interest. The reason they gave was that contracts with a lower guaranteed rate will get less in "bad years" where only the

${ }^{13}$ Cf. e.g., Financial Services Authority (2002). 
guaranteed rate can be paid to all contracts and should therefore be compensated by receiving more in years where surplus is being distributed. We now examine if, from a risk management point of view, such a differentiation in surplus distribution between contracts with different guarantees is appropriate.

Figure 6 shows combinations of the target rate of interest $z$ and the guaranteed rate of interest $g$ for different initial reserve quotas $(x=5 \%$ and $x=20 \%)$. For companies with low reserves we allow the shortfall probability to be $25 \%$, for companies with a high reserve quota, we allow a shortfall probability of 5\%. For both, we assumed an asset allocation containing $10 \%$ stocks.
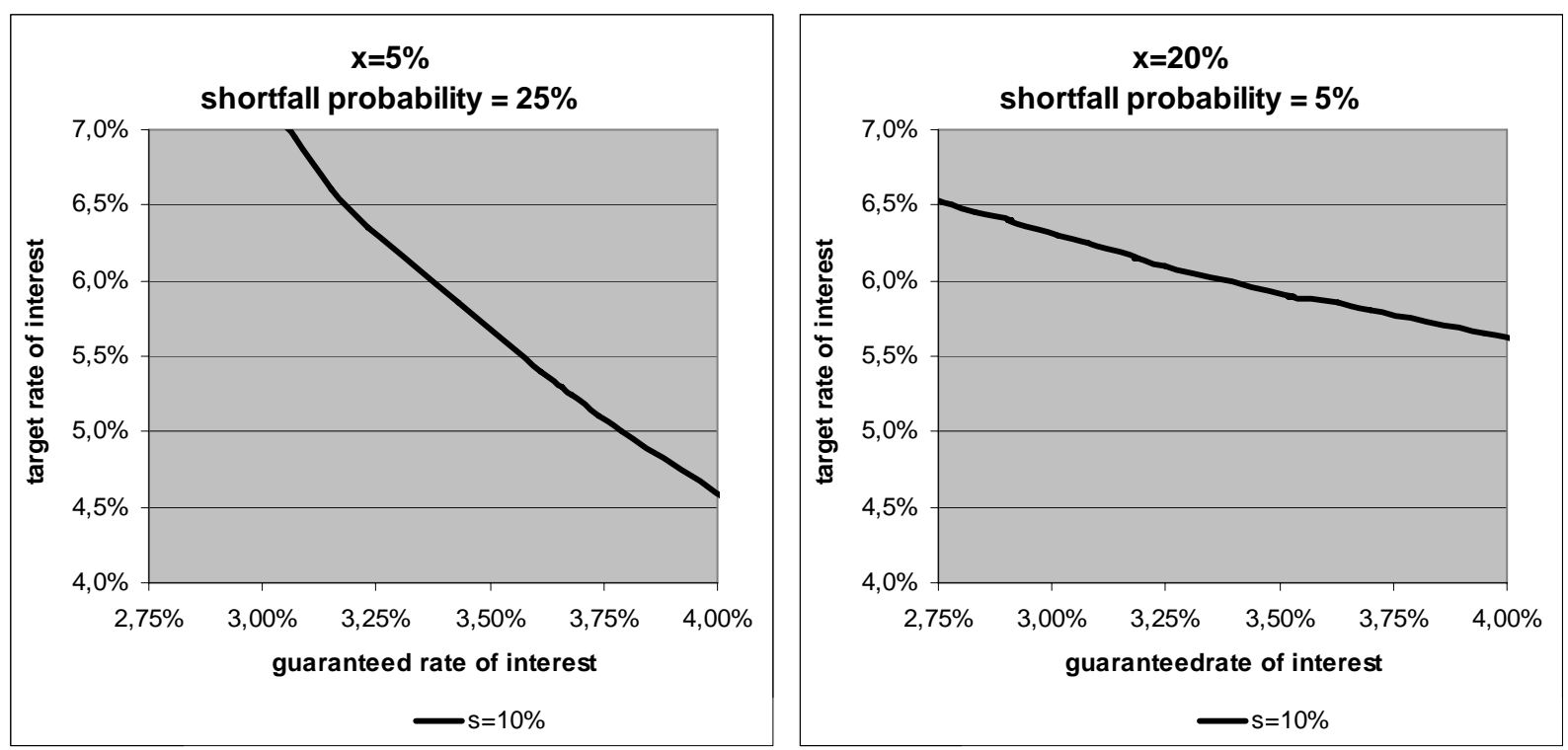

Figure 6 Target rate of interest as a function of the guaranteed rate of interest

Since higher guarantees pose a higher risk to the insurer, from a risk management point of view, it is appropriate for companies to compensate for this by providing a lower target distribution to the contracts with a higher guarantee. It can be seen from the left figure that for companies with low reserves, reducing the target rate by 1 percentage point 
for each percentage point of a higher guarantee keeps the shortfall probability roughly constant.

The chart on the right side of figure 6 is less steep, which shows that for companies with high reserves a lower differentiation in surplus distribution is appropriate. This shows that providing a constant target distribution to contracts with different guarantees - as done in the past - is acceptable as long as reserves are high. Once reserves go down, life insurance companies have to react and change their surplus distribution mechanism if they want to have contracts of equal risk in their liability portfolio. ${ }^{14}$

\subsection{The interaction of regulatory and legal requirements}

So far, our analysis focused on parameters that are subject to management decisions assuming legal requirements to be constant parameters. In the last section of this chapter we will examine the interaction of the different regulatory and legal requirements. We fix any parameters that are subject to management decision, i.e. we set $z=5 \%$ and $s=10 \%$, and let the initial reserves be $x=20 \%$ for the remainder of this section.

In our model, low values of the restriction in asset valuation $y$ correspond to a great degree of freedom with respect to the application of accounting rules. Furthermore, low values of the minimum participation rate $\delta$ correspond to a great degree of freedom with respect to the surplus distribution.

Figure 7a shows the minimum participation rate $\delta$ as a function of the guaranteed rate of interest $g$ for a given shortfall probability of $2 \%$. We show this for different values of $y$

\footnotetext{
${ }^{14}$ See Kling and Russ (2004) for a more detailed analysis of the question of surplus differentiation.
} 
$(y=70 \%$ and $y=90 \%)$. Figure 7b shows the minimum participation rate $\delta$ as a function of the restriction in asset valuation $y$ for different values of the guaranteed rate of interest $(g=$ $2.75 \%$ and $g=4 \%$ ) and a shortfall probability of $2.5 \%$.
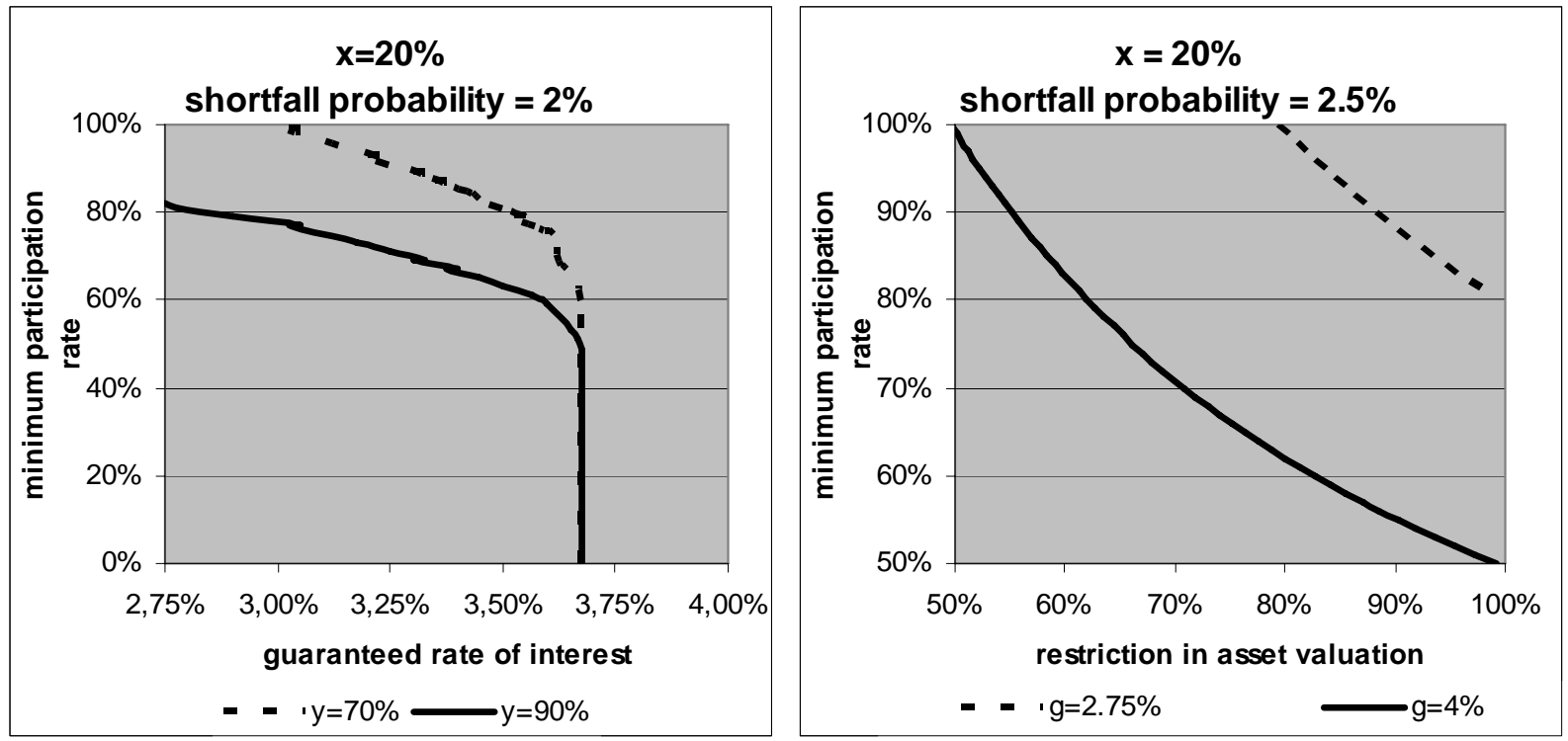

Figure 7a Minimum participation rate as a function of the guaranteed rate of interest (left)

Figure $7 \mathrm{~b}$ Minimum participation rate as a function of the restriction in asset valuation (right)

From Figure 7a we can see that for low values of $\delta$ there is no difference between the different curves for $y=70 \%$ and $y=90 \%$. Thus, if the companies have a high level of freedom in the surplus distribution, they obviously do not need additional freedom in accounting rules.

Further results that are not displayed in detail here show that for companies with low reserves, the guaranteed rate of interest has a very high influence on the shortfall probability. Here, slight changes in $g$ require rather large changes in $\delta$. For companies with high reserves (in the case $y=90 \%$ ), an increase in the guaranteed rate of interest from 
$2.75 \%$ to $3.25 \%$ can be compensated by reducing the minimum participation rate from $82 \%$ to $71 \%$.

Therefore, regulators should allow for lower values of $\delta$ for contracts with a higher guarantee. This again implies that regulators should allow for the total interest (guarantee + surplus) to be the lower, the higher the guarantee.

We also performed simulations for $y \leq 50 \%$. In this case, however, the minimum participation rate has almost no influence on the shortfall probabilities implying that a high degree of freedom in accounting compensates for strict minimum participation rates.

Figure $7 \mathrm{~b}$ also implies that for all guaranteed rates of interest, an increase in $y$ must be followed by less restrictive regulations on surplus distribution. If accounting rules are to be changed bringing book values closer to market values, the minimum surplus distribution parameter $\delta$ has to be reduced or even abolished. Otherwise, the currently predominant form of life insurance will impose a significantly higher risk on life insurance companies than in the past. This should be considered by regulators upon introducing international accounting standards.

\section{Summary and Outlook}

Our analysis shows that shortfall probabilities of life insurance companies are affected by their financial situation, by regulation, market development and management decision. The interaction of these parameters is rather complex and the superimposing effects are not always easy to understand. Nevertheless, since in recent years low interest rates and plunging stock markets posed new risks on insurance companies, it has become more and more important to examine and understand these effects. 
We have developed a general model that provides a framework to analyze the interaction of these parameters and their influence on the financial situation of an insurer. In the present paper we have presented only some of the possible analyses that can be performed within this model. We have, however focused on analyzing what we believe to be the most important effects.

We found that an insurer's shortfall probability increases with an increasing guaranteed rate of interest and with an increasing target rate of interest. For companies with a low reserve situation the influence of the guarantee rate is higher. For companies with high reserves, it is the target rate that plays the major role.

From a risk management perspective, insurance companies should provide a lower target rate of interest to contracts with a high guarantee and a higher target rate of interest to contracts with a low guarantee.

Of course, shortfall probabilities are also increasing with a decreasing initial reserve quota. Concerning the asset allocation, it is not the portfolio with $0 \%$ stocks that represents the least risk. Under our assumptions, the shortfall probability (as a function of the stock ratio s) achieves a minimum at a stock ratio between $9 \%$ and $12 \%$ depending on the other parameters.

Regulators need to consider the financial situation of the individual insurer. Furthermore, in particular when cliquet-style guarantees are included, insurers can only manage such guarantees if they are given a certain degree of freedom in distributing the return on assets. A market value oriented accounting in connection with high minimum participation rates would pose an unmanageable risk to insurers that have issued such contracts. 
The rather high shortfall probabilities throughout our analyses are quite alarming. However, it can be assumed that the absolute values of the shortfall probabilities are lower in all insurance markets where insurers have the possibility to provide terminal bonuses as well as ongoing bonuses. Therefore, including a terminal bonus in the model will be an interesting extension of this work.

Future research should also analyze the influence of a path dependent asset allocation. In this case, the insurer's asset allocation would be determined according to a strategy given by an $F_{t}$-measurable function $s_{t}$ that assumes values in [0;1].

To further understand the influence of the capital markets on shortfall probabilities it would be interesting to perform sensitivity analyses with respect to drift and volatility of stocks and bonds. A next step could be the inclusion of a different asset model with more than two asset classes.

Furthermore, future research could attempt to provide a more detailed model for the liability side of an insurer's balance sheet by modeling a portfolio of different kinds of insurance contracts including mortality effects. 


\section{References}

Bacinello, A.R., 2003. Fair Valuation of a Guaranteed Life Insurance Participating Contract Embedding a Surrender Option. Journal of Risk \& Insurance 70, 461-487.

Briys, E., de Varenne, F., 1997. On the Risk of Insurance Liabilities: Debunking Some Common Pitfalls. Journal of Risk and Insurance 64, 637-694.

Financial Services Authority, 2002. Guidance Note 4 (2002): Resilience Test for Insurers. (http://www.fsa.gov.uk/pubs/guidance/guidance4.pdf)

Grosen, A., Jorgensen, P.L., 2000. Fair Valuation of Life Insurance Liabilities: The Impact of Interest Rate Guarantees, Surrender Options, and Bonus Policies. Insurance: Mathematics and Economics 26, 37-57.

Grosen, A., Jorgensen, P.L., 2002. Life Insurance Liabilities at Market Value: An Analysis of Insolvency Risk, Bonus Policy, and Regulatory Intervention Rules in a Barrier Option Framework. Journal of Risk and Insurance 69, 63-91.

Hansen, M., Miltersen, K.R., 2002. Minimum Rate of Return Guarantees: The Danish Case. Scandinavian Actuarial Journal 4, 280-318.

Harrison, J.M. and Pliska, S.R. (1981): Martingales and Stochastic Integrals in the Theory of Continuous Trading. Stochastic Processes and their Applications 11, 215-260.

Jensen, B., Jorgensen, P.L., Grosen, A., 2001. A Finite Difference Approach to the Valuation of Path Dependent Life Insurance Liabilities. Geneva Papers on Risk and Insurance Theory 26, 57-84.

Kling, A., Russ, J. 2004. Differenzierung der Überschüsse - Betrug an treuen Kunden oder finanzmathematische Notwendigkeit? Versicherungswirtschaft 59, 254-256.

Miltersen, K.R., Persson, S.-A. 2001. Guaranteed Investment Contracts: Distributed and Undistributed Excess Return. Working Paper. Odense University.

Tanskanen A. J., Lukkarinen J. 2003. Fair valuation of path-dependent participating life insurance contracts. Insurance: Mathematics and Economics 33, 595 - 609. 